\title{
The Effectiveness of Acceptance and Commitment Therapy on Quality of Life among Patients with Type 2 Diabetes
}

Narges FathiAhmadsaraei PhD student of Psychology, Islamic Azad University, Isfahan (Khorasgan)branch, Isfahan, Iran .

Hamid Taher NeshatDoost *Department of Psychology, Islamic Azad University, Isfahan (Khorasgan)branch, Isfahan ,Iran. (Corresponding Author) Email:neshat@yahoo.co.uk

GholamReza Manshaee Assistant Professor in Psychology, Islamic Azad University,Isfahan (Khorasgan) branch, Isfahan , Iran.

MohammadAli Nadi

Assistant Professor in Psychology, Islamic Azad University,Isfahan (Khorasgan) branch, Isfahan ,Iran.

Received: 10 April 2016 Accepted: 07 JuNe 2016

\section{ABSTRACT}

Background and objective: Diabetes is one of the chronic disease that has the most negative effects on the quality of life. This study was aimed to investigate the impact of acceptance and commitment therapy (ACT) on quality of life among patients with type 2 diabetes.

Materials and methods: In this quasi-experimental study a pre-test, posttest and a three month follow-up test was used. Among patients from the Diabetes Association in Alborz Province in Iran, 40 diabetic patients were randomly assigned to an experimental and a control group. The instruments for gathering data were demographic characteristics and a shortened form of quality of life questionnaire (DQOL). Besides using their diabetes drugs, during 8 weeks, and each week 2 hours, the experimental group participated in ACT sessions; but the control group only received diabetes drugs. The data were analyzed using covariance analysis, Tukey post hoc test and to compare post-test and medium follow up of two groups the dependent t-test was used through SPSS 20.

Results: ACT in post-test and follow up increased as a psychological intervention of quality of life was used among patients with type 2 diabetes.

Conclusion: ACT can be used as an effective psychological intervention on the quality of life in patients with type 2 diabetes.

Paper Type: Research Article.

Keywords: Type 2 diabetes, Acceptance and commitment therapy (ACT), Quality of life, Karaj, Alborz Province.

Citation: FathiAhmadsaraei N., NeshatDoost H. T., Manshaee G.R., Nadi M.A. The Effectiveness of Acceptance and Commitment Therapy on Quality of Life among Patients with Type 2 Diabetes. Iran J Health Educ Health Promot. Spring 2016;4(1):31-39. 


\section{جكيده}

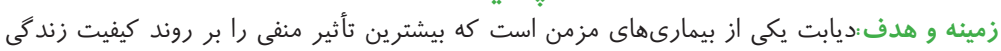

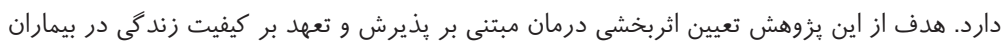

$$
\text { ديابتى نوع دوم است. }
$$

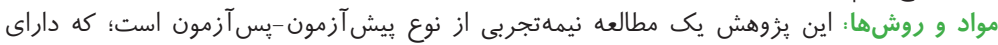

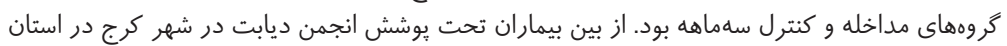

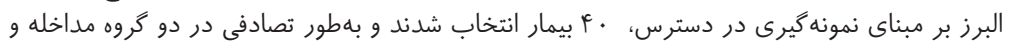

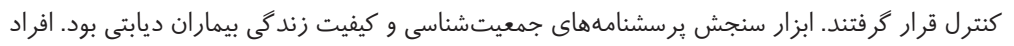

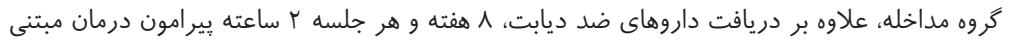

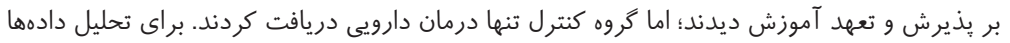

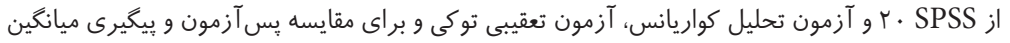

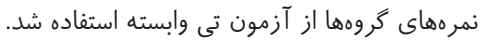

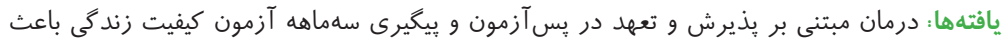

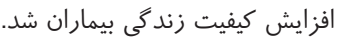

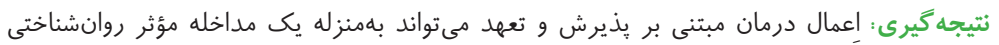

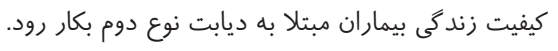

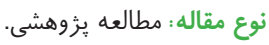
كليدوازه: ديابت نوع دوم، درمان مبتنى بر يذيرش و تعهد، كيفيت زندگى، كرج، استان البرز.

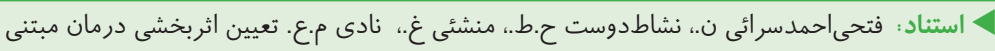

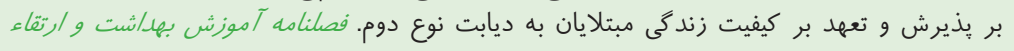

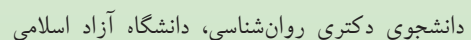
واحد اصفهان (خوراسگان)، اصفهان، ايران حميدطاهر نشاطدوست (خورسكان)، واست

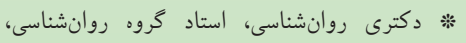

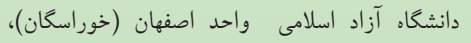
اصفهان، ايران (نويسنده مسئول). Email:neshat@yahoo.co.uk

غلامرضا مثشئى

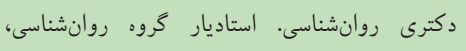

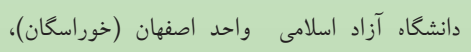
اصفهان، ايران

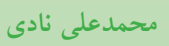

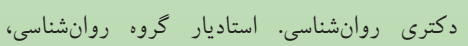

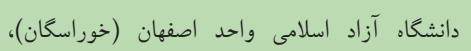
اصفهان، ايران

تاريخ دريافت: بر/ |

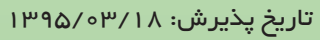


تحريف شناختى، كنترل مشكل و تحليل منطقى است) (1)). برخى يُوهشها نشان دادهاند كه تلاش براى به حداقل رساندن، كنترل و سركوب اضطراب، افكار، درد و غيره سبب توليد مجدد آن مىشود (1) (1). درمان يذيرش و تعهد با رويكردى

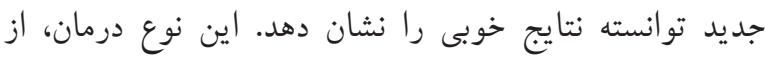
درمانهاى رفتارى موج سوم است كه بر هوشيارى فر اكير، همراه

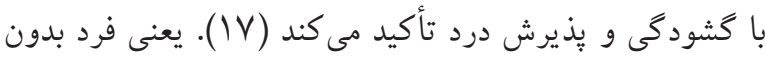

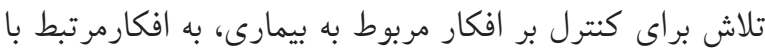

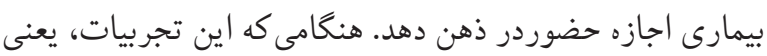

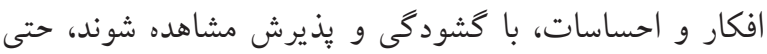

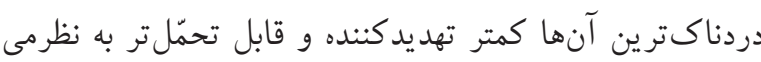
رسند (1) و در عوض اعمال كنترلى غيرمؤثر كاهش مى يابند.

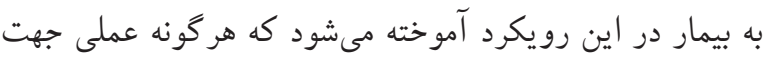

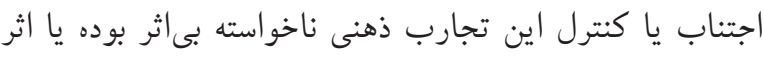

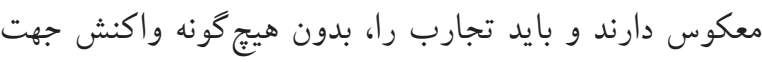

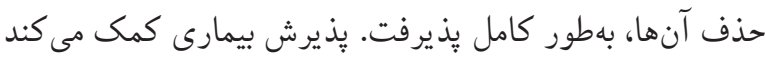

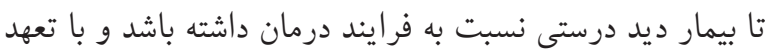

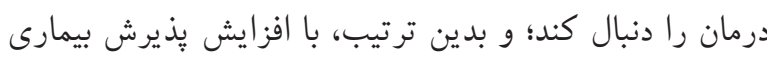

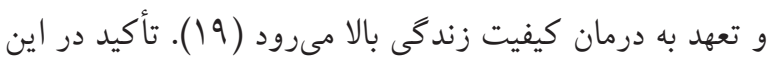

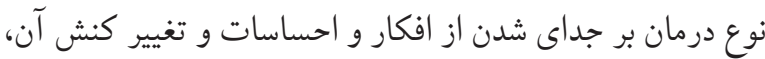
زندگى در لحظه فعلى، تشخيص ارزشها و عمل متعهدانه است

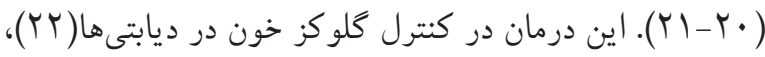
بهبود كيفيت و رضايت زندگى و عملكرد موفق دركنترل

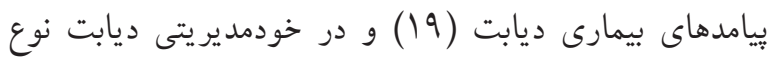

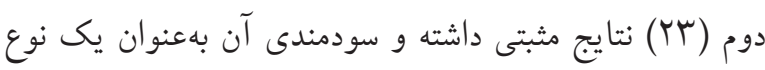
مداخله براى طيف وسيعى از اختلالات مزمن ازجمله اضطراب،

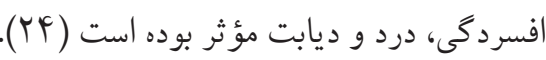

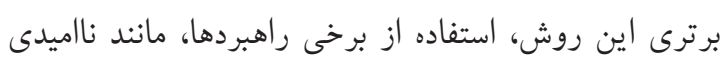

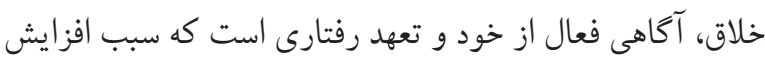
بيشتر تحمل درد، كاهش افكار و احساسات منفى و ارتقا كيفيت زندكى مىشود (1) تا انكيزه جهت درمان افزايش يابد. با افزايش مelod

ديابت شايعترين بيمارى مزمن متابوليك است؛ كه از طريق ناهنجارى در سوختوساز كربوهيدرات، بروتئين و جربى توصيف بريف

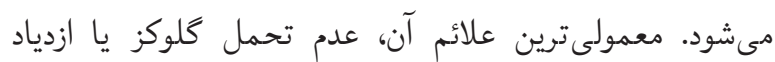

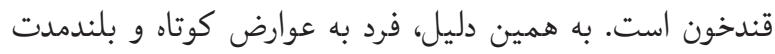

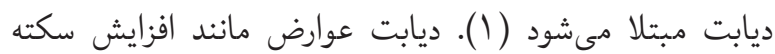
قلبى و مغزى، نارسايى كليوى، نابينايى و قطع عضو دارد (T).

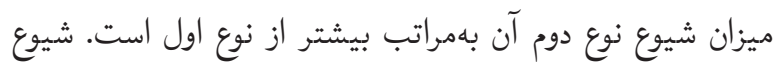

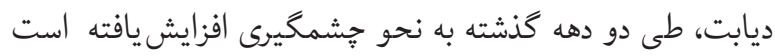

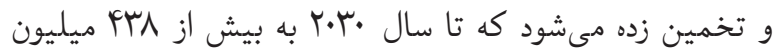
نفر افزايش يابد (ا، r). بين بيمارى و كيفيت زندكى ارتباط متقابل دوسويه وجود

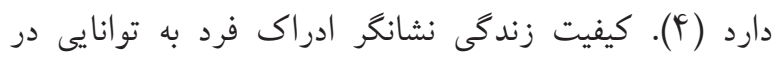
عملكرد خوب در سطح جسمى، روانى و اجتماعى است (ه). بروز

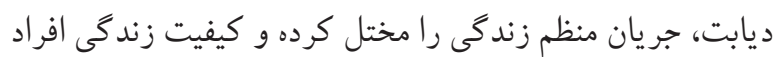

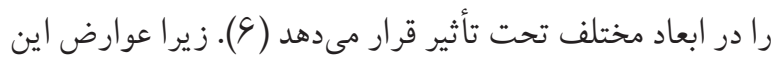

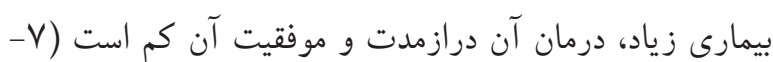
1). اصلاح ("كيفيت زندگى" تنها براى بيماران ديابتى سودمند

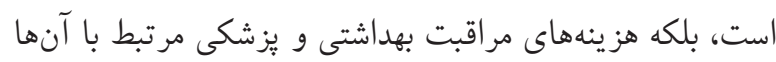
را نيز كاهش مىدهد (9- • (1). رواندرمانى در بيماران ديابتى براني

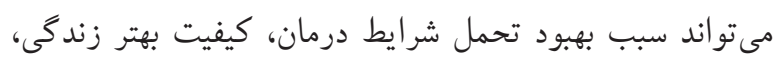

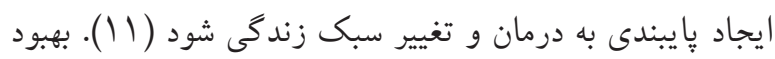
كيفيت زندگى يكى از اهداف اوليه درمان و شاخص مهم درمانى دانى

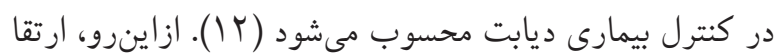
كيفيت زندگى بيماران براى بسيارى از درمانكران، ازجمله

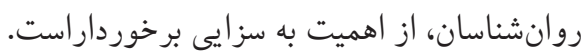

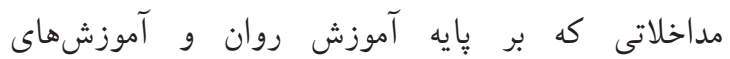
روانشناختى است، از جايكاه و يزٔه برخوردارند. در اكثر تحقيقات إنات

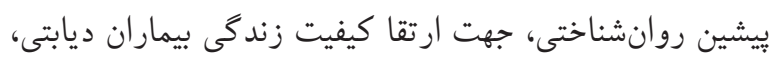

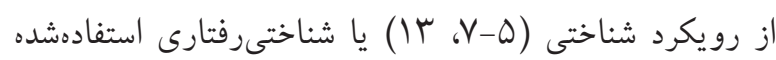
است (IF). هدف از اين رويكرد (اشناسايى و به حداقل رساندن 
عاملى هالينگستد تنظيم شد (YA). فرم كوتاهشه برسشنامه

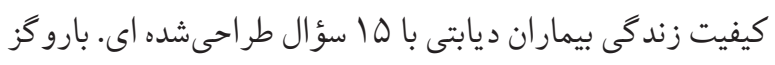

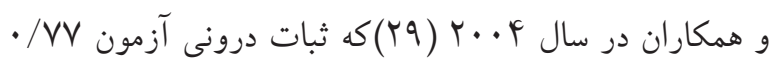

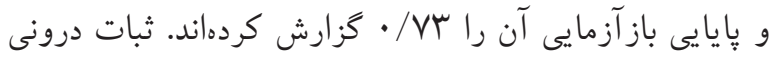

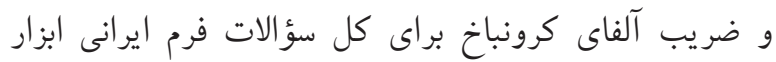

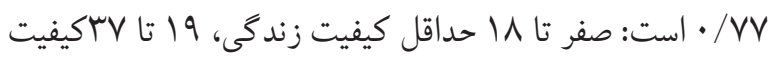

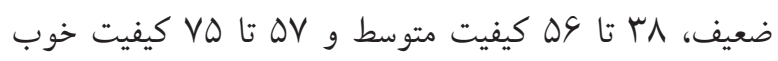

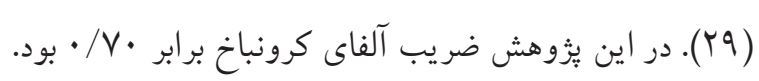

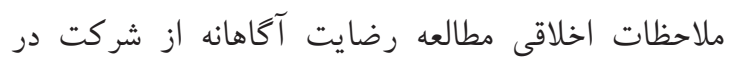

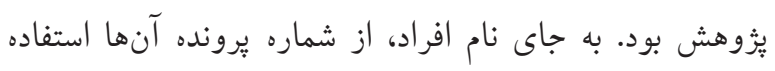

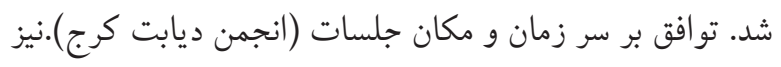

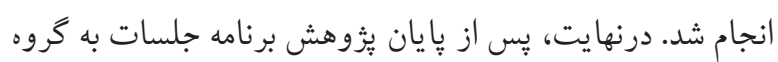
كنترل نيز ارائه شد.

روش اجرا و تحليل: نمره كيفيت زندگى در تمام بيماران

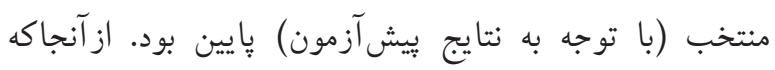

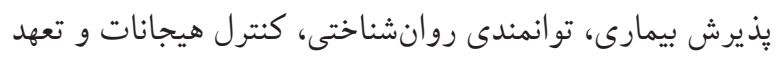

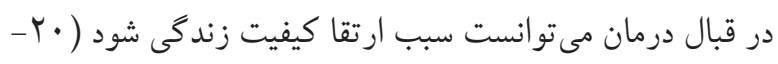

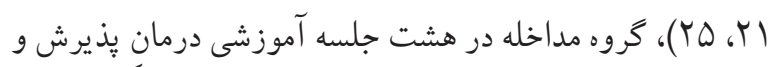

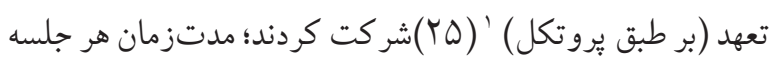
دوساعت بود و موارد آموزشى عبارت بودند از: شناخت مشكلات

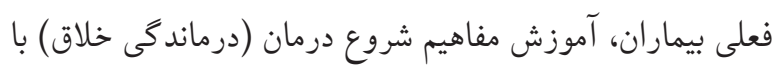

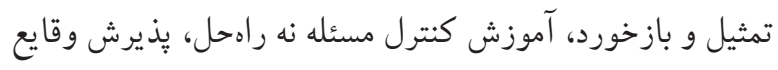
شخصى دردناك بدون كشمكش، كمك براى تشخيص گسلش شناختى (يعنى جدايى بيمارى جسمانى از كل فرايند زندگى) و و

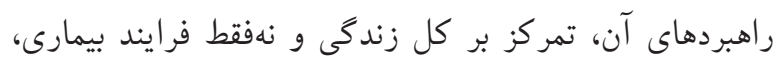

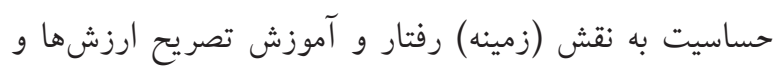

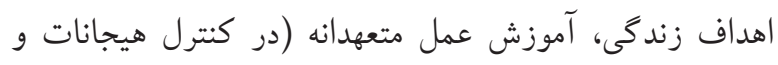

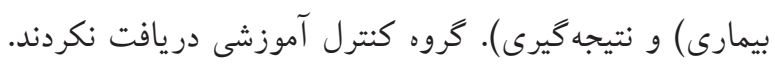

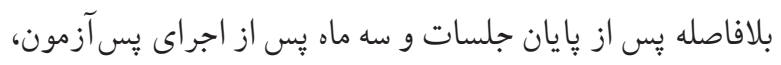

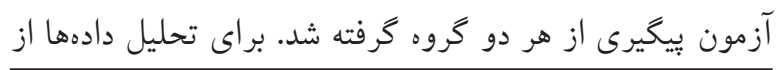

1. The ACT protocol; http://www.health.act.gov.au/sites/default/ files/Number\%205\%20-\%20The\%20Epidemiology\%20of\%20Diabetes\%20Mellitus\%20in\%20the\%20ACT.pdf
انكيزه درمان، مراقبت فرد بيشتر شده و درنتيجه كيفيت زندگى ارتقا

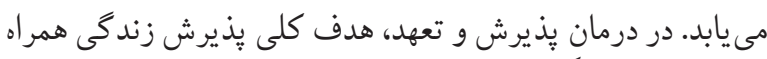

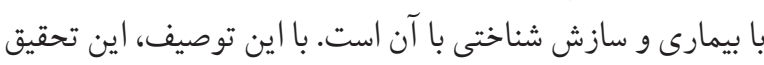

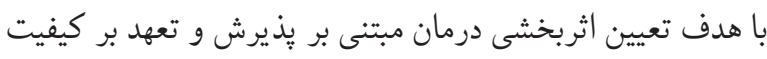
زندگى بيماران ديابت نوع دوم انجام شد. مو اد و روش ها

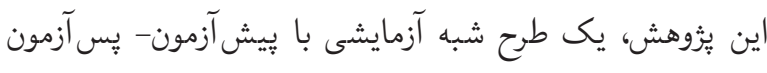

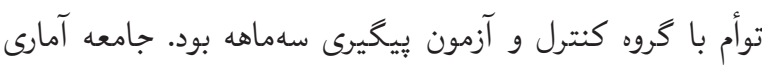

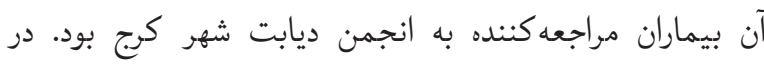

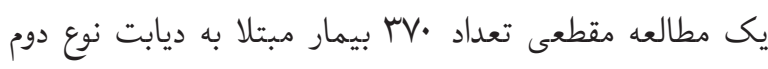

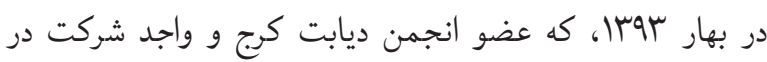

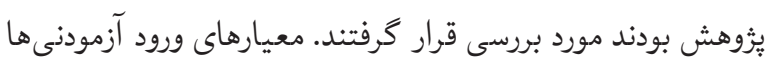

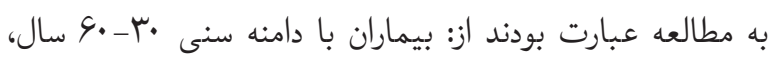

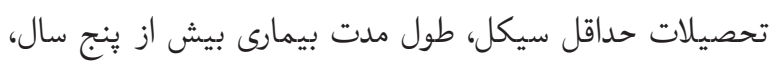

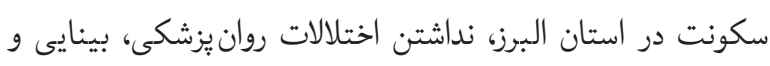

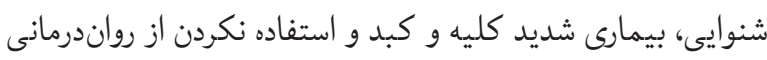
و تغيير دارويى خارج از مداخله يثوهش. معيارهاى خروج آنان نيز ابتلا به ديكر انواع ديابت، بسترىشدن در بيمارستان در طول

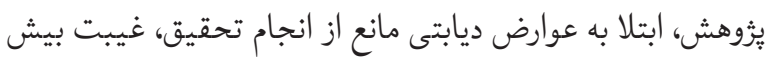

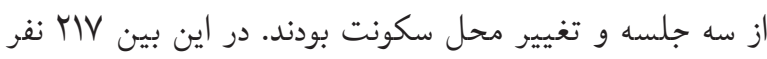

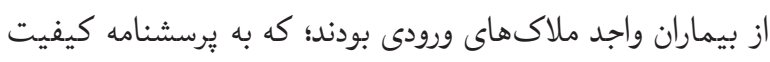

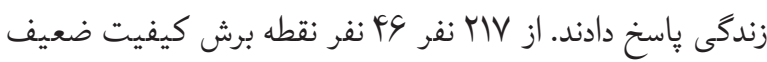

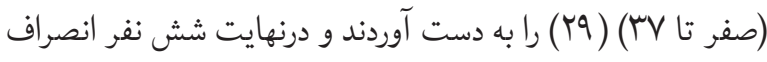

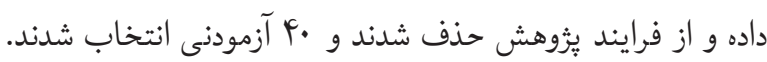
MS Excel سجيس شماره يرونده بيماران منتخب، به نرمافزار وارد شدند و بيماران به شكل تصادفى به دو گروه تقسيم شدند.

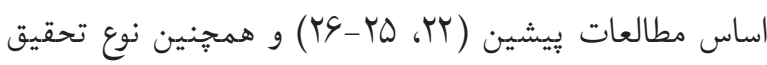

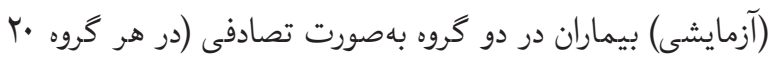

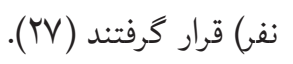

ابزار اين يُزوهش برسشنامه اطلاعات جمعيتشناختى (سن، جنسيت، تحصيلات و شغل) بود؛ كه بر اساس شاخص جهار 
ra

جدول r. ميانگين نمره و انحراف معيار كيفيت زندگَى دو گروه مداخله و كنترل در سه زمان (قبل، بلافاصله و سه ماه بعد از مداخله

\begin{tabular}{|c|c|c|c|c|c|c|}
\hline \multicolumn{2}{|c|}{ بيگيرى } & \multicolumn{2}{|c|}{ يس آزمون } & \multicolumn{2}{|c|}{ بيش آزمون } & \multirow[b]{2}{*}{ كروه } \\
\hline SD & $\mathbf{M}$ & SD & $\mathbf{M}$ & SD & M & \\
\hline $\mathrm{V} / \Delta \Lambda$ & $\mathrm{rq} / \mathrm{V}$ & $V / r G$ & $\mu r / v \Delta$ & $r / v q$ & $r \& / 1$ & آزمايش \\
\hline F/VG & rN/VD & $\Delta / \Delta$. & $r \cdot / r$ & $\Delta / Y F$ & $r \& / 40$ & كنترل \\
\hline
\end{tabular}

ميانكين نمره كيفيت زندگى در دو گروه در ويشآزمون

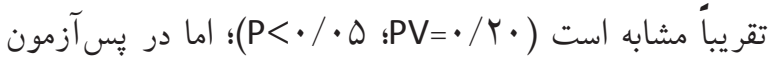
(PV=•/・l) كروه آزمايشى افزايش داشت و در گروه كنترل در سه زمان

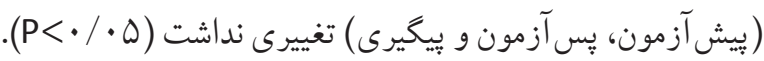

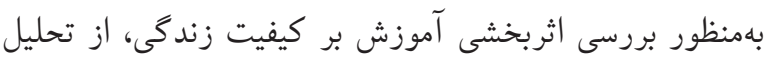

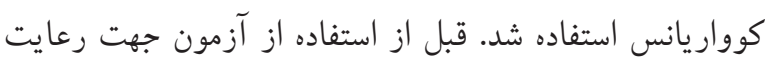

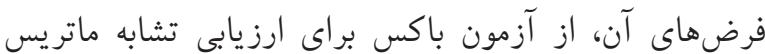

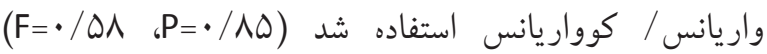

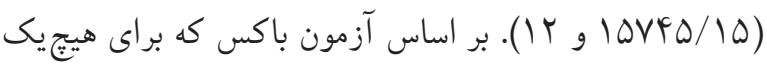

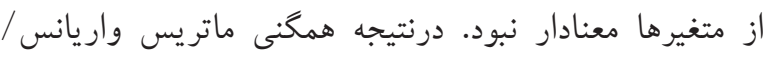

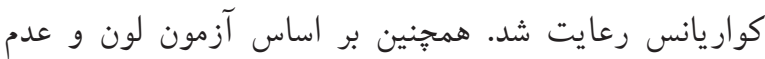

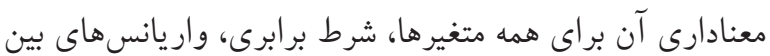

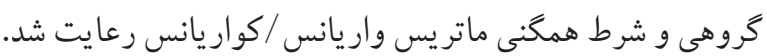

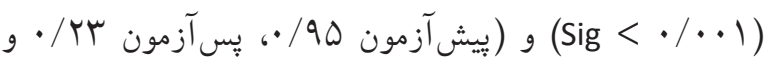

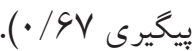

جدول سّ. نتايج آزمون تحليل كوواريانس جهت بررسى اثربخشى

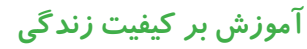

\begin{tabular}{|c|c|c|c|c|c|}
\hline Sig & df & فرضيه & $\mathbf{F}$ & 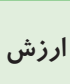 & \\
\hline$\cdot / \ldots$ & $11 f$ & r & $\mathrm{V} / \mathrm{V} r$ & . $/ 4 T$ & اثر بيلايى \\
\hline$\cdot / \ldots$ & $11 \%$ & f & N/9. & $\cdot / \Delta \mathrm{V}$ & لامبداى ويلكز \\
\hline$\cdot / \ldots$ & 11. & r & $1 . \%$ & $\cdot / \mathrm{V}^{\mu}$ & اثر هتلينگ \\
\hline$\cdot / \ldots$ & $\Delta V$ & r & $r \cdot / \mathrm{r}$ & $\cdot / V Y$ & بزرگترين ريشه خطا \\
\hline
\end{tabular}

· P و آزمون تحليل كواريانس، آزمون تعقيبى توكى و SPSS

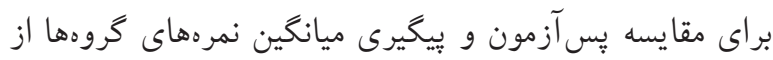
آزمون تى وابسته استفاده شد.

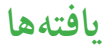
ميانكين سن گروه مداخله F

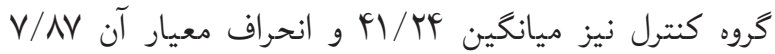
بود. بين گروه مداخله و كنترل تفاوت آمارى معنادارى مشاهده

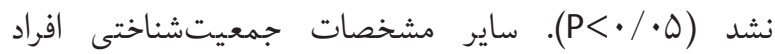
موردمطالعه در جدول ا ارائهشده است. مطابق جدول إمتغيرهاى جمعيتشناختى و كيفيت زندگى در دو گروه تفاوت آمارى معنادارى مشاهده نشد (ه • (P> (P) جدول ا. مقايسه ميانگين نمره اوليه كيفيت زندگى در افراد كروه مداخله و كنترل برحسب متغير هاى جمعيتشناختي

\begin{tabular}{|c|c|c|c|c|c|c|c|}
\hline \multicolumn{3}{|c|}{ گَروه كنترل } & \multicolumn{3}{|c|}{ گرقوه مداخله } & \multirow{2}{*}{\multicolumn{2}{|c|}{ متغير }} \\
\hline معنادارى & انحراف & ميانگين & معنادارى & انحراف & ميانگين & & \\
\hline \multirow{2}{*}{$/ \mu$} & $s / \cdot r$ & $r \Delta / \Delta r$ & \multirow{2}{*}{$\cdot / r \mid$} & $\Delta / Y F$ & $r F / \cdot D$ & زن & \multirow{2}{*}{3} \\
\hline & $\Delta / f^{4}$ & TF/AT & & $r / 99$ & $r s / V T$ & مرد & \\
\hline \multirow{3}{*}{$\cdot / r r$} & $V / \cdot F$ & rr/rk & \multirow{3}{*}{$\cdot / 11$} & $\Delta / F 1$ & $r s / f$. & زير دييلم & \multirow{3}{*}{$\begin{array}{c}\text { s. } \\
\frac{3}{3} \\
\frac{1}{3} \\
3\end{array}$} \\
\hline & $r / \mu r$ & rs/rA & & $\Delta / 4$. & $m F / \Delta l$ & دييلم & \\
\hline & $r / \mathcal{F}$ & س & & $s / 41$ & rT/rA & كارشناسى & \\
\hline \multirow{2}{*}{ • } & $F / 94$ & $r \Delta / \Delta l$ & \multirow{2}{*}{ • } & S/FT & 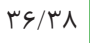 & $r \Delta-\mu$. & \multirow{2}{*}{3} \\
\hline & $\Delta / \Delta F$ & rI/fr & & $s / \mathbb{F V}$ & $r \cdot / \mu r$ & $s \cdot-14$ & \\
\hline \multirow{3}{*}{$\cdot|q|$} & $r / r \mu$ & $\mu \cdot / \mu \wedge$ & \multirow{3}{*}{$\cdot / r \Delta$} & $s / F$. & $r 1 / r q$ & خانهدار & \multirow{3}{*}{ 3.3 } \\
\hline & $V / r q$ & $r Y / \Delta F$ & & $V / \Delta r$ & $r q / \mu r$ & كارمند & \\
\hline & $r / A V$ & & & $r / r \mu$ & II/To & آزاد & \\
\hline
\end{tabular}

سنجش كيفيت زندگى هر گروه در سه مرحله قبل، بعد و سه ماه پِ از اعمال متغير مستقل (يذيرش و تعهد) انجام شد.

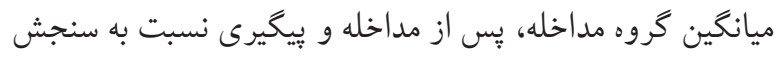

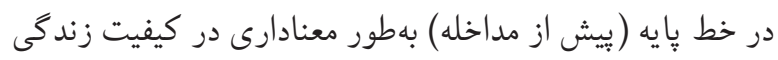
افزايش داشت؛ ولى در گروه كنترل در هر سه مرحله تغيير معنادارى نداشت (جدول ب ك). 
(جدول 1) و كيفيت زندگى در دو گروه تفاوت آمارى معنادارى

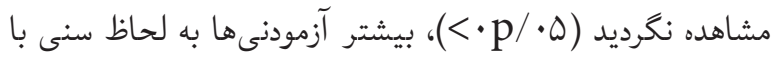

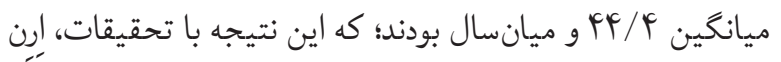

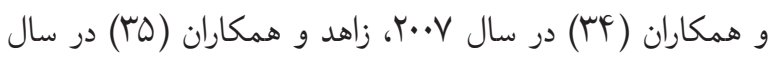

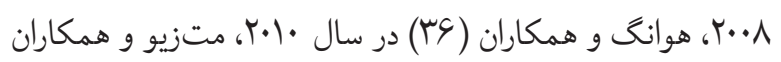
(TV)

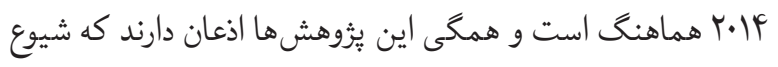

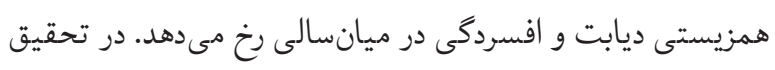

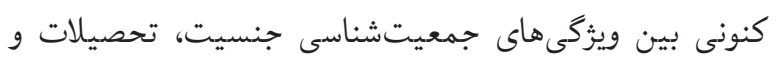
شغل و كيفيت وِيين زندكى تفاوت آمارى معنادارى مشاهده

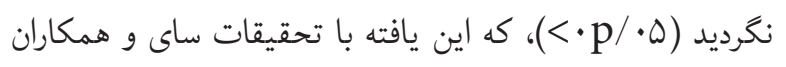

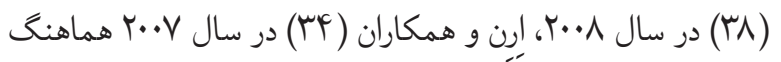

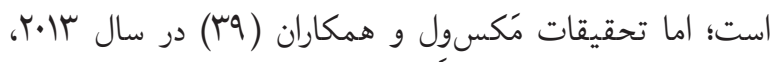

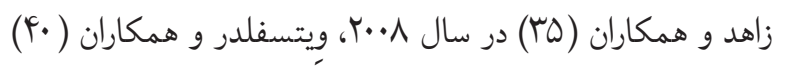

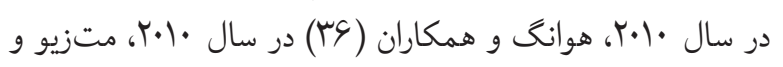

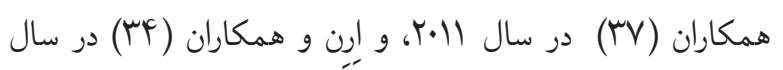

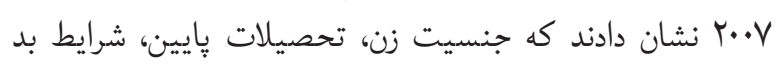

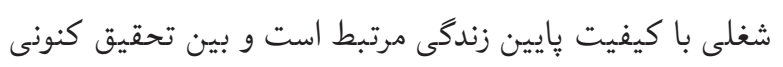

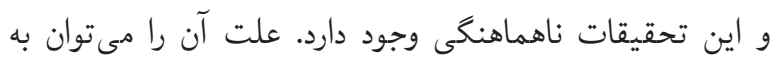

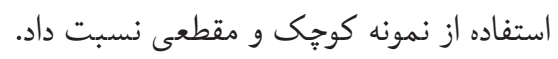

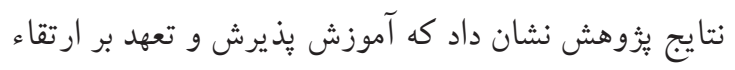

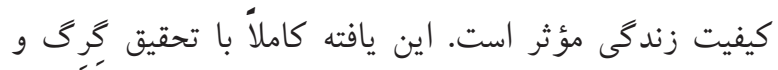

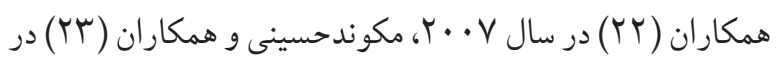

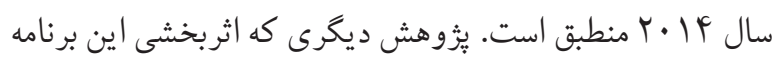
آموزشى بر كيفيت زندكى بيماران ديابتى را موردبررسى قرار

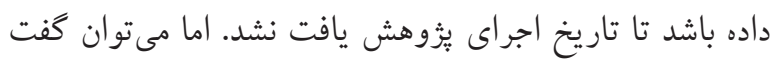

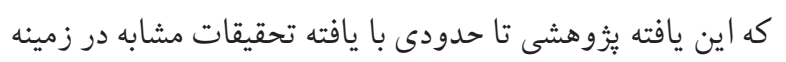

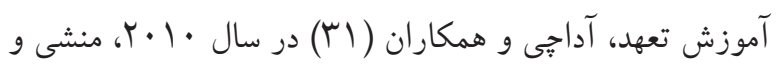

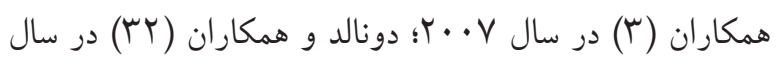

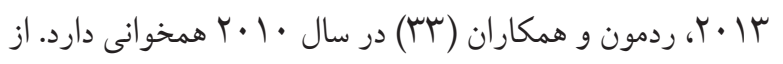

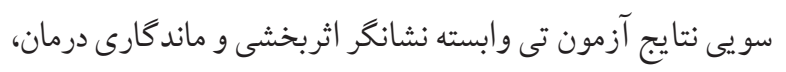

همانطور كه در جدول r مشاهده مىشود بين دو گروه،

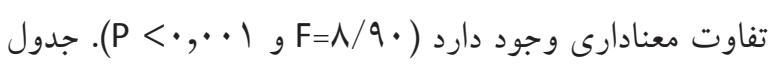

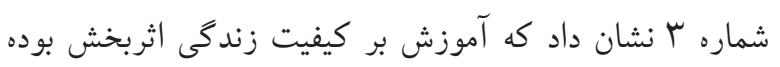
است. جدول أ تفاوت بين گروهها را نشان مىدهد:

\section{جدول عا. نتايج تفاوت بين گَروهى آموزش بر كيفيت زندگى}

\begin{tabular}{|c|c|c|c|c|c|c|}
\hline اندازه اثر & Sig & F & مجذوراتين & df & مجذورات & كروه \\
\hline.$/ 99$ & $\%$ & lorA & $r . . q r$ & 1 & $r . . q r$ & آزمايش \\
\hline$\cdot|4|$ & r & $r / T q$ & $4 / 19$ & 1 & $8 / 19$ & كنتر ل \\
\hline
\end{tabular}

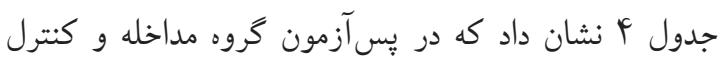

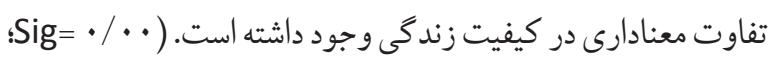

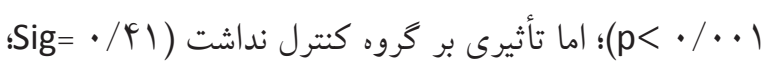

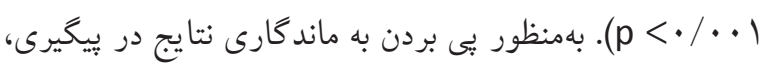

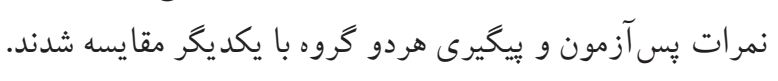
جدول ه. نتايج آزمون t وابسته مقايسه پֶ آزمون و يِيخيرى كيفيت زندگى در دو گروه

\begin{tabular}{|c|c|c|c|c|c|}
\hline Sig & $\mathbf{t}$ & انحراف معيار & ميانكين & مرحله & كروه \\
\hline \multirow{2}{*}{.1 .10} & \multirow{2}{*}{$-r / \Delta r$} & $V / r G$ & rm/vo & يس آزمون & \multirow{2}{*}{ آزمايش } \\
\hline & & $\mathrm{V} / \Delta \mathrm{A}$ & $\mu q / \nu$ & يِيگيرى & \\
\hline \multirow{2}{*}{.$/ 1 r$} & \multirow{2}{*}{$1 / \Delta \Delta$} & $\Delta / \Delta$. & $r \cdot / r$ & يس آزمون & \multirow{2}{*}{ كنترل } \\
\hline & & $\Delta / r G$ & $r V / \Delta \Delta$ & پِيگيرى & \\
\hline
\end{tabular}

در جدول ه نتايج آزمون تى وابسته براى كيفيت زندكى در ييخيرى تفاوت معنادارى نسبت يس آزمون داشت. بحث در طول · r سال اخيو، علاقهمندى به بهبود كيفيت زندگى بيماران

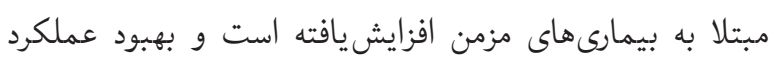

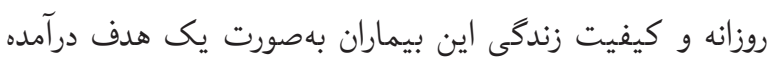
است (•r). هدف از انجام يزوهش حاضر، تعيين اثربخشى درمان

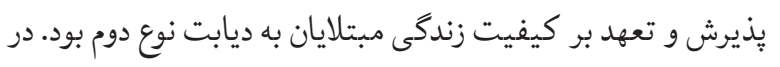

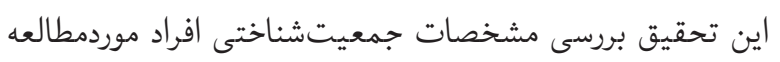


مداخله مشابهى بر روى ساير انواع ديابتها نيز صورت يذيرد. ييشنهاد مىشود اين يثوهش با نمونهاى بزرگتر و با ييخيرى بلندمدت تكرار شود. همجٍنين، برنامه اختصاصى درمان يذيرش و تعهد، از سوى متخصصين، براى بيماران ديابتى طراحى شده و ادغام رسمى اين آموزش در برنامه درمانى مراقبتى ديابت موردتوجه صاحبنظران فعال در اين زمينه قرار كيرد. نتيجه كيرى

بر اساس يافتههاى اين مطالعه، درمان يذيرش و تعهد با ايجاد يذيرش تجربيات ناخواسته بيمارى كه خارج از كنترل شخصاند و همجنين تعهّد در جهت عمل سبب بهبود كيفيت زندگى در بيماران مبتلا به ديابت نوع دوم شد. نتايج اين درمان در يس آزمون و يِيحىى باعث بهبود كيفيت زندكى شده است كه

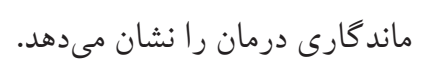

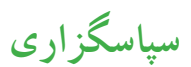

يثوهش حاضر با همكارى انجمن ديابت در استان البرز و بيماران عضو اين انجمن انجام كرفت. لذا از تمامى دوستانى كه ما را در اين يثوهش يارى دادند، كمال قدردانى مىشود.

\section{References}

1. Meusel L, Kansal N, Tchistiakova E, Yuen W, Maclntosh B, Greenwood C, et al. A systematic review of type 2 diabetes mellitus and hypertension in imaging studies of cognitive aging: time to establish new norms, Front Aging Neurosci. 2014; 6: 148. Full Text.

2. Egede L, Ellis C, The effect of major depression on preventive care and quality of life among adults with diabetes. Elsevier. 2010;16: 10-12. Full Text

3. Munshi D, Khalida I, Rachel J, Martin P. Diabetes, Common Mental Disorders, and disability: Findings From the UK National Psychiatric Morbidity Survey.Psychosomatic Medicine: 2007; (69) 6: 543-550. Full Text

4. Papelbaum M, Lemos H.M, Duchesne $M$, Kupfer $R$, Moreira R.O, Coutinho W.F, The association between quality of life, depressive symptoms and glycemic control in a group of type 2 diabetes patient. Diabetes research \& clinical practice.2009;89:227-238. Full Text.

5. Schram M T, Baan C A, Pouwer F. Depression and Quality of Life in Patients with Diabetes: A Systematic Review from the European Depression in Diabetes (EDID) Research Consortium. Curr Diabetes Rev. 2009; 5(2): 112-119. Full
در بهبود كيفيت زندگى بيماران است ( ( • / / P ) كه اين يافته با تحقيقات گرگ و همكاران (YT) در سال V . . . . مكوندحسينى

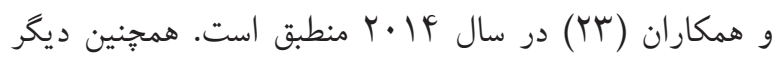
تحقيقات مشابه در زمينه تأثير گذيرش در ارتقاء كيفيت زندگى

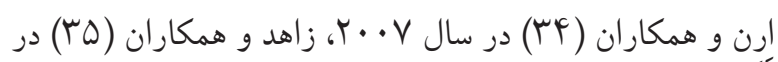

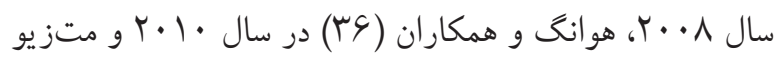
و همكاران (YV) در سال I| • ب نيز بر اين يافته اذعان دارند كه تلاش جهت انكار بيمارى كمكى به بيمار نمى كند؛ ولى پذيرش و جالش درست سبب بهبود فرايند بيمارى شده و با بهترشدن روند درمانى، كيفيت زندگى ارتقا مى يابد.

يكى از محدوديت هاى اين يثزوهش، استفاده از مطالعه مقطعى بود. ماهيت جند رشتهاى بودن يثزوهش (روانشناختى و يزشكى) نيز باعث شد كه درمان يزشكى كنترل نشود. يروتكل اجراشده در اين يزوهش يك برنامه اختصاصى براى بيماران مبتلا به ديابت نبود؛ بلكه يك برنامه عمومى آموزشى درمان يذيرش و تعهد بود. صرف انتخاب بيماران ديابت نوع دوم نيز از ديخر محدوديتهاى يزوهش بو. به همين سبب جهت تعميم نتايج يِيشنهاد مىشود

Text.

6. Adachi M, Yamaoka K, Watanabe M, Nishikawa M, Hida E, Kobayashi I, et al. Effects of lifestyle education program for type 2 diabetes patients in clinics: study design of a cluster randomized trial. BMC Public Health. 2010; 10: 742-749. Full Text.

7. Gillibrand W, Holdich P. Supporting people with diabetes related stress and depression, diabete Evidence-Based Management 21 Practice Nursing. 2010; 21: 7-21. Abstract.

8. Kitzler T. M, Bachar M, Skrabal F, Kotanko P. Evaluation of treatment adherence in type 1 diabetes: A novel approach. European Journal of Clinical Investigation. 2007; 37: 207213. Abstract.

9. Barnard K.D, Lloyd C.E, Holt R.I.G. Psychological Burden of Diabetes and What It Means to People with Diabetes. Psychology and Diabetes Care. 2012; 1-22. Full Text.

10. Pena M, Hernandez V, Fernandez X, Gil A, Perez M,Lopez $A$, Andres $R$, et al. Self-perception of health status, mental health and quality of life among adults with diabetes residing in a metropolitan area. Diabetes Metab.2010; 36(4): 305-311. Abstract/FREEFull Text. 
11. Maxwell M, Harris F, Hibberd C, Donaghy E, Pratt R, Williams $C$, et al. A qualitative study of primary care professionals' views of case finding for depression in patients with diabetes or coronary heart disease in the UK. 2013; 2296 (1471): 14- 46. Abstract.

12. Choi Y, Lee M, An SY, Kim TH, Kim HJ, Chung YS, et al. The Relationship between Diabetes Mellitus and HealthRelated Quality of Life in Korean Adults. The Fourth Korea National Health and Nutrition Examination Survey (20072009). Diabetes Metab J.2011; 35 (6): 587-594. Full Text.

13. Ellis DA, Templin T, Conningham PB, Podolski CL, Cakan N. Mult systemic therapy for adolescents with poorly controlled type I diabetes, Stability of treatment effects in a randomized controlled trial. Journal of Consulting and Clinical Psychology 2007; 75(1): 168-74. FREE Full Text.

14. Egede LE, Ellis C. The effects of depression on diabetes knowledge, diabetes self-management, and perceived control in indigent patients with type 2 diabetes. Diabetes Technol Ther. 2008; 10(3):213-219. Full Text.

15. Hayes S. C, Pistorello J, Levin M. Acceptance and Commitment Therapy as a Unified Model of Behavior Change. 2012; 40(7): 976-1002. Full Text.

16. Blarrina M, Luciano C, Martinez O, Valdivia S, Valverde M, Ortega J. Coping With Pain in the Motivational Context of Values Comparison Between an Acceptance-Based and a Cognitive Control-Based Protocol Behavior Modification. Publications sage pub. 2008; 32(3): 403-422. Full Text.

17. Zettle R, Rains J, Hayes S. Processes of change in acceptance and commitment therapy and cognitive therapy for depression: A mediation reanalysis of Zettle and Rains. Behavior Modification. 2011; 35(3): 265- 283. Abstract.

18. Hayes S, Luoma J, Bond F, Masuda A, Lillis J. Acceptance and commitment therapy: model, processes and outcomes. Behaviour Research and Therapy. 2006; 44: 1-25. Abstract/FREE Full Text.

19. Forman E. M, Herbert J. D, Moitra E, Yeomans P. D, Geller P. A. A randomized controlled effectiveness trial of acceptance and commitment therapy and cognitive therapy for anxiety and depression. Behavior Modification. 2009;36:1-28. Abstract/FREE Full Text.

20. Smout M, Acceptance and commitment therapy. Pathways for general practitioners. Psychological strategies. 2012; 41(9): 672- 676. Abstract.

21. Powers M. B, Vording M, Emmelkamp P. M. Acceptance and commitment therapy: A meta-analytic review. Psychotherapy and Psychosomatics. 2009; 78:73-80. Abstract.

22. Gregg J. A, Callaghan G.M, Hayes S.C, Glenn L. Improving diabetes self-management through acceptance, mindfulness, and values: A randomized controlled trial. Journal of Consulting and Clinical Psychology, American Psychological Association. 2007;75(2): 336-343.
23. Makvand Hosseini Sh, Rezaii M, Azadi M. Effectiveness of acceptance and commitment group therapy on the selfmanagement of type 2 diabetes patients. J clin psycho. 2014; 5(4):2-1. http://jcp.semnan.ac.ir/files/site1/user_ files_091e30/nazifi-A-10-247-51-8c5521c.pdf

24. Pull C. B, Janca A. Current empirical status of acceptance and commitment therapy. Personality disorders and neurosis: Current Opinion in Psychiatry. 2009; 22(1): 5560. Abstract.

25. Gillibrand W Holdich P (2010) Supporting people with diabetes related stress and depression, diabete EvidenceBased Management. Practice Nursing. 2010;21)7(:32-39. FREE Full Text.

26. Soczynska J, Konarski J, Hanna O, Woldeyohanne S, Candy W, Miranda A, Kennedy S.D. Should Depressive Syndromes be reclassified as "Metabolic Syndrome Type II"?. American Academy of Clinical Psychiatrists, Clinical Psychiatry.2011; 19(4):257-264. Full Text.

27. Dlavr A. [Research in psychology and education]. 3st ed. Tehran. nashre virayesh. 2010;54. [Persian] Full Text.

28. Hollingshead A.B. Four Factor Index of Social Status [cited Oct 01 1975]. Available at: URI: http://hdl.handle. net/10477/1879 htm

29. Nasihatkon A. pishva A. Habib Zadeh F. Tabatabai M. Taher $M$. Hogat $F$, et [Determine the reliability and validity of clinical summary quality of life questionnaire (DQOL) in Farsi (Persian)]. Diabetes and Lipid Iranian Journal 2012; 11 (5): 483-487. [Persian]. Full Text.

30. Pibernik M, Ajdukovic D, Vucic lovrencic M, Hermanns $\mathrm{N}$. Does treatment of sub syndromal depression improve depression and diabetes related outcomes: protocol for a randomised controlled comparison of psycho-education, physical exercise and treatment as usual, 2011, 12:17-27. Full Text

31. Adachi M, Yamaoka K, Watanabe M, Nishikawa M, Hida E, Kobayashi I, Tango T. Effects of lifestyle education program for type 2 diabetes patients in clinics: study design of a cluster randomized trial. BMC Public Health, 2012; 10: 742-749. Full Text.

32. Donald M, Dower J, Coll JR, Baker P, Mukandi B, Doi SA. Mental health issues decrease diabetes- specific quality of life independent of glycaemic control and complications: findings from Australiass living with diabetes cohort study. Health and Quality of Life Outcomes 2013; 11:1. Full Text.

33. Redmon J. B, Bertoni A. G, Connelly S, Feeney P. A, Glasser S. P, Glick H. Effect of the look AHEAD study intervention on medication use and related cost to treat cardiovascular disease risk factors in individuals with type 2 diabetes. Diabetes Care. 2010; 33, 1153-1158. Full Text.

34. Eren I, Erdi $O$, sahin M. The effect of depression on quality of life of patients with type Ildiabetes mellitus.Wiley-Liss, Inc. 2007; 25(2): 98-106. Abstract. 
35. Zahid N, Asghar S, Claussen. Depression and diabetes in a rural community in Pakistan. Diabetes Res Clin Pract. 2008;79(1):124-127. Full Text.

36. Huang MF, Courtney M, Edwards H, McDowell J. Factors that affect health outcomes in adults with type 2 diabetes: a cross-sectional study. Int J Nurs Stud 2010; 47(5): 542549. Full Text.

37. Matziou V, Tsoumakas K, Vlahioti E, Chrysicopoulou L, Galanis P, Petsios K, et al. Factors influencing the quality of life of young patients with diabetes. J Diabetes. 2011; 3(1): 82-90. Full Text.

38. Tsai KW, Chiang JK, Lee CS. Undiagnosed depression in patients with type 2 diabetes. BMC Public Health. 2008;20:44-48. Abstract.

39. Maxwell M, Harris F, Hibberd C, Donaghy E, Pratt R, Williams C. A qualitative study of primary care professionals' views of case finding for depression in patients with diabetes or coronary heart disease in the UK. Psychology and Diabetes Care. 2013; 2296 (1471): 14- 46. Full Text.

40. Waitzfelder B, Gerzoff RB, Karter AJ, Crystal S, Bair MJ, Ettner SL, et al. Correlates of depression among people with diabetes: The Translating Research In to Action for Diabetes (TRIAD) study. Clinical Psychiatry.2010;4: 215222.. Full Text. 